\title{
Patterns of Beliefs, Attitudes, and Characteristics of Teachers That Influence Computer Integration
}

\author{
Julie Mueller $^{1}$ and Eileen Wood ${ }^{2}$ \\ ${ }^{1}$ Faculty of Education, Wilfrid Laurier University, 75 University Avenue West, Waterloo, ON, Canada N2L 3C5 \\ ${ }^{2}$ Psychology Department, Wilfrid Laurier University, 75 University Avenue West, Waterloo, ON, Canada N2L 3C5
}

Correspondence should be addressed to Julie Mueller, jmueller@wlu.ca

Received 9 March 2012; Revised 26 September 2012; Accepted 26 September 2012

Academic Editor: Eric Z. F. Liu

Copyright ( $\odot 2012$ J. Mueller and E. Wood. This is an open access article distributed under the Creative Commons Attribution License, which permits unrestricted use, distribution, and reproduction in any medium, provided the original work is properly cited.

\begin{abstract}
Despite continued acceleration of computer access in elementary and secondary schools, computer integration is not necessarily given as an everyday learning tool. A heterogeneous sample of 185 elementary and 204 secondary teachers was asked to respond to open-ended survey questions in order to understand why integration of computer-based technologies does or does not fit with their teaching philosophy, what factors impact planning to use computer technologies in the classroom, and what characteristics define excellent teachers who integrate technology. Qualitative analysis of open-ended questions indicated that, overall, educators are supportive of computer integration describing the potential of technology using constructivist language, such as "authentic tasks" and "self-regulated learning." Responses from "high" and "low" integrating teachers were compared across themes. The diversity of the themes and the emerging patterns of those themes from "high and low integrators" indicate that the integration of computer technology is a complex concern that requires sensitivity to individual and contextual variables.
\end{abstract}

\section{Introduction}

Digital technologies, and in particular computer technologies, are salient features at all levels of education today. Despite widespread access, however, computer-based technologies continue to be underutilized and the potential of these technologies as instructional tools is not being realized [1-3]. This problem has been evident for some time and continues to be an issue in both national and international contexts [4-10]. Integrating technology as a meaningful learning tool involves much more than simply providing equipment. Instead, integration of computerbased technologies can be seen as a "craft" [1] that evolves as educators adapt their teaching styles, beliefs, and practice. In order to promote mastery in the "craft," it is important to investigate the specific role teachers as individuals play in the process of technology integration. The current study employed qualitative research methodology with a heterogeneous sample of practicing teachers to gain an in-depth understanding of how computer technologies fit within teachers' repertoire of instructional tools and their own perceptions about what it is to be a technologyusing teacher. By surveying a random sample of teachers from across an entire school district, this study presents a comprehensive picture of the beliefs and attitudes of the "average" teacher in elementary and secondary schools across the district.

Computer technologies may be uniquely challenging innovations to be integrated as instructional tools within the curriculum, in part, because the technologies available change rapidly. In order to keep up with continuous change in hardware, software, and instructional innovations that accompany advancements in computer technologies [11] educators are required to constantly update their technological knowledge [12] and adapt their teaching practices. The continual changes may result in teachers being "perpetual novices" in the process of technology integration [2]. Rather than representing a linear progression in skills through a stage-like development [13], the integration of computer technologies can be characterized as a recursive spiral [14] where advancement requires an ongoing reconciliation of previous skills along with adaptation to new requirements. 
The continual and rapid advancement inherent to computer technology, therefore, may itself inhibit the adoption and integration of this technology within some classrooms.

Historically, predictors such as access to technologies and technical concerns have often been identified as important inhibitors of computer integration [2]. Although the advancements associated with computer technologies may present a challenge for integration, advancements alone may only account for some of the reluctance to integrate technologies especially given the prevalence of a myriad of digital technologies in most schools in the Western world and internationally (e.g., [15-17]) and the increased use of computers among the population in general. For example, evidence from early, short-term longitudinal studies demonstrate significant increases in computer use and decreases in technical issues over periods as brief as two years [18].

Recent research, therefore, has begun to look beyond external or technical constraints as the issues most central to explaining underutilization and, instead, focuses on issues internal to the individual by including measures of teachers' beliefs and attitudes $[2,6,19-24]$. These variables have been shown to be significant predictors of computer integration.

Two theories/frameworks are particularly relevant in the attempt to explain how multiple influences interact in teachers' choices regarding integration of computers: cost expectancy theory and technological pedagogical content knowledge (TPACK). [24] used cost-expectancy theory to identify how teachers balance the relative merits of several variables in their decisions to integrate computer technologies. Cost-expectancy theory proposes that teachers consider value (beliefs about the contributions technology provides) and expectancy (efficacy beliefs, access, and support available), and then weigh that against cost (including time, energy, anxiety, teacher numbers) in their decision to implement computer technology in their classrooms. The results of their survey of elementary and secondary teachers indicated that the important predictors of implementation were expectancy of success and perceived value-that is, teachers' attitudes toward technology and the likelihood that they can accomplish their goal. The diminished emphasis on costs lends support for the idea that barriers to computer integration are lessening and that a focus on a teacher's attitudes and perceptions is required.

Mishra and Koehler's [25] technological pedagogical content knowledge (TPACK) framework, however, emphasizes teacher knowledge rather than attitudes and beliefs, suggesting that an integrated understanding of content, pedagogy, and technology is a critical foundation for successful integration of technology. They propose that TPACK is more than an additive construct of knowledge and skills but is a complex understanding of how technology and pedagogy interact within a specific content base. It is not sufficient to have the technology and know how to use it, but teachers need to be comfortable in the knowledge of how to use that technology with best teaching practice in their content area. Integration of computer technologies can lead teachers to question their current instructional approach and develop new teaching strategies [25, 26]. Koehler and Mishra's [27] TPACK framework approaches teaching with technology as a "complex, ill-structured task," that requires educators to "develop new ways of comprehending and accommodating this complexity" (page 62). It is important to understand what questions and changes teachers encounter. The most efficient way to acquire this information is by asking teachers directly what factors they consider when planning for and integrating the use of technology in their classrooms and from teachers' answers we can determine what form TPACK may take.

Existing literature points toward some critical factors that affect teachers' decisions regarding integration of computers. For example, Vannatta and Fordham [23] surveyed K-12 teachers to identify the impact of factors including teaching philosophy, teacher self-efficacy, openness to change, professional development, technology training, use of computers by teachers and students, gender, and teaching experience. The variables that were significant predictors of computer integration included number of hours teachers put in beyond their contractual work, the number of hours of technology training, and openness to change. However, these variables accounted for only $18 \%$ of the variance. Vannatta and Fordham [23] called for additional study of the complexity of the "development of a skilled, reflective technology-using teacher" (page 262) that includes random sampling of a large, heterogeneous sample and a variety of teacher attributes, both technology and nontechnology specific.

One variable that may be particularly salient for teachers is whether the use of computers matches with their existing pedagogy. The impact of the pedagogical beliefs of teachers on classroom practice has been well documented [2832 ], but the direct influence on technology integration is not as clear [24]. In general, teachers are likely to use their past experiences, beliefs, and attitudes about learning and teaching to develop their beliefs about technology as a teaching method or instructional tool, depending on how they classify computers [33-37]. Their attitudes and beliefs about learning and teaching influence how they think about technology. To use computers as a cognitive tool in knowledge construction, educators must acknowledge the computer as a learning tool and be able to incorporate it into the classroom. Several researchers have demonstrated that it is not sufficient to know how to use computers in order to use them effectively in the classroom [38-40] instead it is necessary that teachers receive instruction and experiences that allow them to integrate both good pedagogy and good practice with respect to using computers $[23,34$, 39]. Given that educators ultimately determine whether and how computers will be used in their classroom [41, 42], it is critical to understand, from their perspective, what influences their decisions and behaviors.

Consistent with this recognition of the importance of the interaction between pedagogy and technology, recent research indicates that teacher training that integrates pedagogy along with hands-on computer applications yields greater integration, greater confidence among teachers, and beliefs that they will integrate computers as part of their instruction $[39,43,44]$. Given this evidence, it is important to further explore teachers' beliefs with respect to instruction involving the use of computers [21, 40]. In addition, to 
understand the complex linkages between content, pedagogy, and technology use, it is important to first understand what teachers believe constitute "good teaching" in order to determine whether good teaching with technology differs from good teaching in other contexts. The present study draws upon the recommendations of existing research and further explores pedagogical issues and beliefs of teachers in order to enhance our understanding of "teacher characteristics" that contribute to the successful integration of computer technologies.

\section{Method}

2.1. Participants. Participants included 185 elementary teachers and 204 secondary teachers randomly selected from the complete list of teachers employed by one large Canadian school board (representing both urban and rural schools) to ensure that the sample was inclusive of teachers with diverse technology and teaching experience. The Canadian public school system is comprised of two levels of instruction: elementary (Kindergarten to grade 8 , entry at 4 years of age) and secondary (grades 9 to 12). The sample of teachers represented 94 of the 99 elementary schools and each of the 16 secondary schools in the board. The majority of teachers were female (146 female and 39 male elementary teachers; 116 female and 88 male secondary teachers). The mean age of the teachers was 41.8 years $(\mathrm{SD}=8.43)$ with average teaching experience of 14.8 years $(\mathrm{SD}=8.75)$. The majority of teachers had a university degree ( $87.2 \%$ elementary, $78.3 \%$ secondary) and an additional $10 \%$ of elementary teachers and $15.3 \%$ of secondary teachers held Masters or Ph.D. degrees.

Participants were teaching at schools that ranged from a small population of less than 200 to a large population of over 1500 . Among the elementary teachers, the majority of participants $(63.2 \%)$ were regular classroom teachers with a smaller proportion involved in special education (11.4\%), language instruction/support (12.5\%), or combined duties. Elementary teachers represented assignments ranging from Kindergarten to grade 8. Among the secondary teachers, participants taught in a variety of curriculum areas.

2.2. Measures. Teachers completed one survey. Eight questions using a 5-point, Likert-type scale ranging from 0 (never) to 4 (a great deal) were aggregated to create a composite measure of computer integration (alpha $=.82$ ) which was used to identify "low" and "high" computer integrating teachers. The computer integration measure incorporated a multiplicity of behaviours (i.e., computer use by both students and teachers for a variety of purposes) in order to capture the complexity of computer integration.

Five open-ended questions measuring teacher's beliefs and attitudes toward computer integration and teaching were developed based on past research identifying critical teacher variables that could potentially impact computer integration (e.g., $[2,24,33,35])$. The first two questions asked the participants to select a Yes or No response followed by
TABle 1: Percent of participants responding to each qualitative question.

\begin{tabular}{lcc}
\hline Question & Elementary & Secondary \\
\hline $\begin{array}{l}\text { (1) Teacher support for computer } \\
\text { integration in their division }\end{array}$ & 81.6 & 86.8 \\
$\begin{array}{l}\text { (2) Teacher response to whether } \\
\text { integration fits with their instructional } \\
\text { style }\end{array}$ & 75.7 & 78.9 \\
$\begin{array}{l}\text { (3) Teacher planning_factors } \\
\text { influencing decision to integrate } \\
\text { computers }\end{array}$ & 85.4 & 91.2 \\
$\begin{array}{l}\text { (4) Personal characteristics of excellent } \\
\text { teachers }\end{array}$ & 97.3 & \\
$\begin{array}{l}\text { (5) Personal characteristics of teachers } \\
\text { effectively integrating computer }\end{array}$ & & \\
technology & 31.9 & 42.0 \\
\hline
\end{tabular}

instructions to elaborate on their answer. The five questions were as follows.

(1) Do you support the concept of integrating computer technology for students in your division?

(2) Does the integration of computer technology fit within your personal instructional style?

(3) When you are planning a lesson/unit, what factors make you decide to integrate the computer?

(4) If you had to define the personal characteristics of people who are excellent teachers, what would those characteristics be?

(5) Please identify characteristics that make excellent teachers who happen to integrate technology effectively, different from excellent teachers who do not.

2.3. Procedure. Teachers were mailed a paper-and-pencil survey along with a stamped, addressed return envelope. A large majority of participants answered each question (more than $75 \%$ ) except for the question that asked how excellent teachers who used technology were different from those who do not, where less than fifty percent of participants responded (see Table 1).

The responses to the five open-ended questions were examined using an inductive coding technique [45] to develop categories or labels for responses. Participants' language was used as much as possible to produce a "datadriven" coding scheme [46]. Emerging themes were recorded as responses were read and similar responses were then grouped under more abstract headings [47]. To protect against "projection" and to ensure reliability of the coding scheme, an explicit code of theme labels, definitions, and examples was developed [48]. The resulting coding scheme for each question was used to code $25 \%$ of the data by two independent raters with percentage agreement ranging from 81 to $94 \%$ agreement. Codes were compared and discrepancies were resolved through discussion between the two coders [48]. Adjustments were made to the themes and definitions, and the resulting coding scheme was used to code the entire response set. 
Following extraction of themes from the entire sample, patterns of responses from "low" and "high" integrating teachers were compared by examining differences in the patterns for each theme. "High" integrators represented the $25 \%$ of teachers with the highest scores on the aggregated computer integration measure and "low" integrators represented the $25 \%$ of teachers with the lowest integration scores.

\section{Results and Discussion}

3.1. Support for Integration of Computer Technologies. Teachers were asked if they "support the concept of integrating computer technology for students in [their] division?" (Yes/No) and were then asked to explain their answer. The majority of teachers supported the concept of integrating technology (98.4\% and $98.5 \%$ for elementary and secondary teachers, resp.).

Five key themes explained responses for those who did support the integration of technology. Those teachers saw computer technology as an efficient and pedagogically current tool. It was described as a tool that improves the efficiency of existing tasks or teaching methods (e.g., "integrate research on-line with the students producing their work in the lab instead of writing on paper to cut out a step") and a tool that offers additional pedagogical choices, such as "hands-on learning." Supportive teachers talked about integrating computer technology as a necessary skill. Technological knowledge and skill was seen as a life or academic skill that students would need in the future. Responses within this theme included references to the necessity of "keeping current" with the world of today's children and/or supporting children's existing skills and/or experience (e.g., "gets them ready for grade 1" or "necessary skills for future"). Computer technologies were also presented as valuable resources in terms of hardware, software, or available information. Some teachers identified the value of technology for specific curriculum areas while others discussed it more generally as a good resource (e.g., "many types of software and websites to enhance my teaching in wide variety of subject areas" or "I feel that integrating computers in the areas of math and language are the most beneficial and easy to do"). A smaller number of educators talked about computer technologies as being motivating or adding variety. The computer was identified as a motivational tool that gets students involved and captures their attention and/or provides variety in instruction and learning (e.g., "The students love it and I always try to give them a new task before playtime"). The smallest percentage of responses were categorized under a theme defined as individualized or differentiated instruction for students with specific needs, such as students learning English or students with learning disabilities (e.g., "When I am working with various special education students at different levels, computers are very useful").

Although the number of teachers who did not support the integration of computer technology was limited, five themes were extracted from their responses. Of the five themes, four dealt directly with barriers to computer integration that had to do with physical resources or personal training. An additional theme identified computer technology as an inappropriate tool for instruction. Lack of support for computer technology was linked to insufficient resources, including lack of availability in terms of number of computers, quality of computers, software, as well as human resources related to class size and technical support (e.g., "When things do not work (printers, Internet), the lesson falls apart"). For some teachers, computer technology was viewed as an inappropriate instructional tool. The reasons for this ranged from inappropriateness for the children's age or developmental level to a particular topic or subject (e.g., "As long as computer technology is used for learning beyond itself, I do not think grade ones need computer for the sake of computer"). These responses also suggested that the focus needs to be on other skills such as social skills, writing, and reading. A few educators listed barriers that have been traditionally found in the literature about computer integration: time in terms of learning to use it, setting it up, and completing activities (e.g., "It takes time to become familiar with our changing software"); comfort and skill of teachers (e.g., "With more training the teachers would feel an increased level of comfort with the concept of integrating technology"); and, access barriers, as challenges in getting access to computers when needed due to scheduling, location, or the logistics involved in getting children to or on the computers (e.g., "but it is very difficult to take a class of 20 JK students to the lab by myself").

Pedagogy was a key explanation for teachers who indicated support for the integration of computer technology. Teachers were supporting technology based on student learning and pedagogical considerations - that is, how the technology fits with learning and instruction. A teacher's pedagogical beliefs drive their practice and understandably, their choice of instructional and learning tools. Recent research [34] has suggested that a teacher's pedagogical beliefs do indeed match their practice and that professional development should be addressing instructional beliefs and attitudes toward technology. Those few teachers who did not support the integration of technology within their teaching also spoke to pedagogy and learning with reference to computers as inconsistent or "inappropriate" based on the age and stage of development of the students and other more preferred teaching methods. These teachers more frequently indicated technical and logistical barriers as reasons that they did not support the integration of computer technology.

The fact that teachers who do and do not support integration identify different reasons for their decisions highlights the need to be cautious when extrapolating from recent trends in the literature. Specifically, several studies (e.g., [2, 18, 34]) have demonstrated an apparent shift from technological barriers as a primary source for limiting teacher's integration of technology. However, the current study shows that resource barriers do continue to be a concern, particularly for teachers who are less likely to support the integration of technology. It has been assumed that increased familiarity and use of technology among the general public and among teachers have reduced barriers to integration. However, the rapid rate of change in technology 
and the teachers' perceptions about their own level of skill may make computer technologies a daunting challenge to add to the classroom. The majority of teachers, however, indicated a belief that computer technology is appropriate for the children they are teaching and for their own instruction.

Recent research emphasizes the importance of classroom specific knowledge rather than general knowledge as a precursor for effective use of technology in education. For example, [38] demonstrated that even pre-service teachers who were "digital natives," those who had grown up surrounded by computers and who were fluent in computer use for personal use, needed training to understand how to effectively adapt computers as a tool for the classroom. The TPACK framework of technology integration [27] suggests that technology integration is intricately intertwined with pedagogical knowledge, which is supported here in teachers' discussions of pedagogy and child development. Varied interventions need to be developed to address the perceived strengths and weaknesses of integrating computer technologies if teachers are to be able to act on their beliefs that computer technology should be integrated into the classroom.

3.2. Comparison of High and Low Integrators on Support for Integration of Computer Technologies. Although the majority of teachers were supportive of technology in theory, those who report more fully integrating technology (i.e., "high" integrators) and those who are "low" integrators may differ on their pattern of responses apart from the general sample. An examination of the prevalence of themes as a function of level of integration is depicted in Figure 1. The overall pattern of responses including each theme is similar for the high and low integrators. One notable difference is that the percentage of high integrators endorsing each theme is much higher than low integrators. It appears that high integrators have more explicit and full reasons for their support or lack of support for computer technology integration. High integrators greatly endorsed integration of computers as a pedagogical tool. The salience of pedagogical issues is also evident when high and low integrators who do not support the integration of technology are compared.

Figure 2 presents the pattern of themes for teachers not supporting the integration of computer technology. As expected, the proportion of responses from low integrators was much higher than the proportion of responses from high integrators. However, it was interesting that some high integrators did not support the integration of computers for their division. The presence of high integrators in this category at all suggests that external factors (e.g., board or school policies/practice requirements) may be responsible for some teachers' participation in computer integration.

\subsection{Computer Technology Integration and Fit with Instruc-} tional Style. The responses to the question regarding the fit between teacher's instructional style and integration of computer technologies also resulted in both positive and negative responses, with the majority of responses being positive $(92.4 \%$ and $93.5 \%$, elementary and secondary, resp.). Eight themes captured responses explaining how

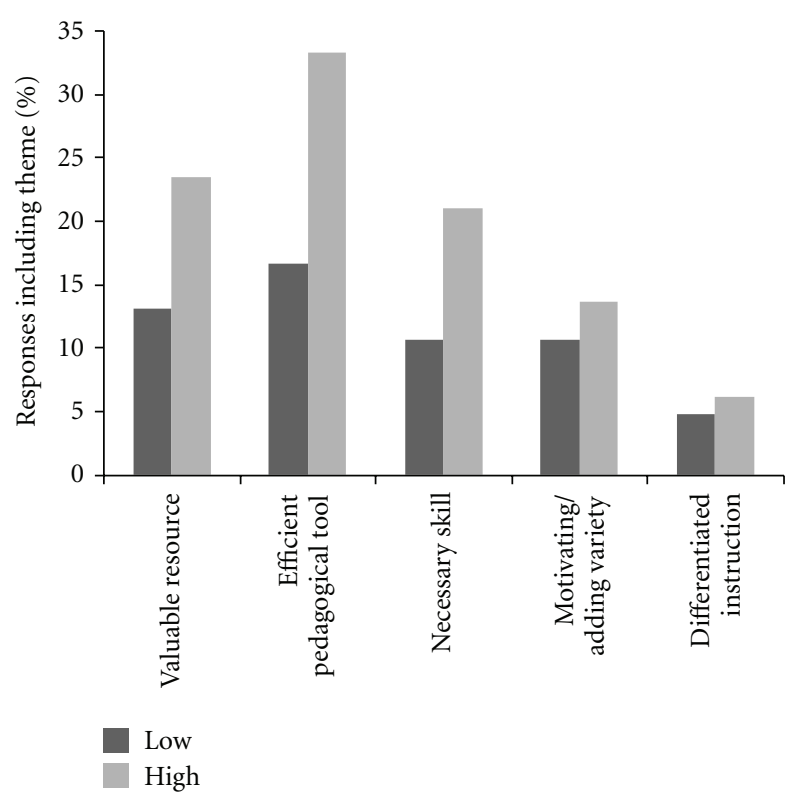

Figure 1: Patterns of themes by integration level for supporting the concept of integrating computer technology for students.

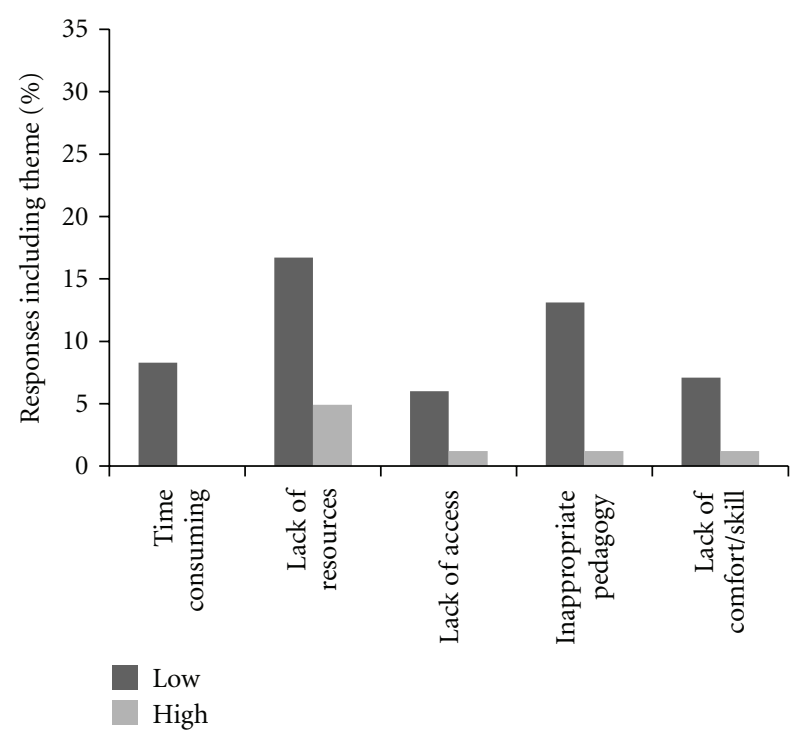

FIGURe 2: Patterns of themes by integration level for not supporting the concept of integrating computer technology for students.

integration fitted with teachers' instructional styles and five themes explained how computer integration did not fit with teachers' instructional styles. Teacher's instructional style had to be inferred, as it was often not stated explicitly.

The largest number of comments suggested that computer technology should be used as another tool that assists students in their learning on its own or to complement other tools, often described as being more efficient or easier, and adding variety to methods already being used (e.g., "I use computers as a tool, an easier or more effective way to learn material or report information" or "I consider the computer to be a very useful and dynamic tool"). 
Responses also indicated a belief that integration of computer technology allows students to take control of their own learning as self-regulated learners and work independently to meet specific goals. Using computers was seen as providing choice and feedback for the learner (e.g., "I like for students to have the freedom to work at their own pace and explore their own special interests within an area of study" or "students take control of their learning when using computers. It is a less teacher directed lesson").

The third theme supported the idea that computer technology can provide practical and authentic learning tasks. Specifically, teachers mentioned that computer technologies allow students to be active constructors of knowledge and take part in their learning (e.g., "I believe in hands-on learning so I often take my students to the lab to have them try different things" or "to show notes, provide handouts and other hands-on learning, computers are essential to my teaching style").

A less frequent theme was related to a teacher's comfort and/or experience with computer technology. Responses in this category often indicated that teachers felt that their comfort with technology meant that it did not "interfere" with their style (e.g., "I feel comfortable using computers and want my students to feel the same" or "It does not always suit the topic, but I am comfortable enough with computers that it does not hamper my style").

A smaller percentage of responses indicated that it is important to integrate technology to keep current. In addition, there were responses that recognized that technology is part of students' lives outside of school (e.g., "I believe in being current. ..computers are changing and I want to keep students up to date").

A further theme covered responses suggesting that computer technology allows for differentiation and individualized instruction according to language, disabilities, learning styles, and multiple intelligences (e.g., "depends on the student and planning for what her capabilities are" or "I like to teach on different learning styles and multiple intelligences. Computers are another tool to let me do this").

Computer technology was also seen as motivating or encouraging for students to learn. Teachers find students engaged when they use computer technology (e.g., "I like how computers engage my students and motivate them").

The final of the eight themes captured comments related to positive student outcomes and characteristics (e.g." "student performance has improved since I started using my laptop in teaching").

Many of the themes that indicated computer technology fits with a teacher's instructional style describe a constructivist approach to teaching (e.g., self-regulated learning, differentiated learning, motivates learning, practical/authentic), suggesting that instructional style may be an important factor in adoption and integration of technology within the classroom. In addition, perceiving computer technologies as one of many instructional tools is also an important issue. Indeed, the largest percentage of respondents described computer technology as an effective, efficient, and complementary tool for instruction.
The reasons for integration of computer technologies "not fitting" with a teacher's instructional style were less varied with only 5 themes emerging. The most common theme was related to resources-respondents suggested that computer technology did not fit with their philosophy because of the many technical problems, lack of resources, and so forth (e.g., "I'd love to use it more but there are too many restrictions, such as not having enough computers" or "I also have only 30 minutes per day with each class. This would probably become 20 minutes if I tried to walk a class to the computer lab and back during the French period").

Teachers also indicated that they were not comfortable with technology or needed training and knowledge (e.g., "as a newer teacher, it is sometimes hard to integrate subjects, let alone computers").

There was limited mention of pedagogy in the themes describing why computer integration did not fit, generally teachers stated a preference for other methods, for example, class discussion, paper and pencil (e.g., "I am more of a discussion-oriented teacher"). Teachers also spoke to pedagogy by suggesting that computer technology was socially isolating and does not allow for interaction (e.g., "I do like to be animated in front of my students and sometimes computers do not allow this").

The final theme captured a very few comments that suggested that the integration of technology does not match their curriculum or ministry policies around standardized testing (e.g., "sometimes pressure to cover curriculum interferes" or "I strongly believe that students need to be taught the skills of software/hardware use. Hard to find the time to do this with the mandated curriculum of the ministry and policies of the (school board)").

Although there were a variety of themes to explain how computer integration fitted or did not fit with instructional style, only the issue of comfort appeared in both responses, with greater comfort reflecting positive responses and less comfort reflecting negative responses. Otherwise, teacher's explanations of what did and did not explain the fit between computer integration and teaching style were unique to the positive or negative response.

Our themes suggest two things. It could be the case that even within this same school board there are "have" and "have not" schools with some schools simply having more resources and more trained personnel for support. Alternatively, it could be that the sample represents teachers in the early stages of integration as well as those who are more advanced and have surpassed the barriers that do exist (e.g., [13]).

3.4. Comparison of High and Low Integrators to Fit with Instructional Style. Comparisons of the pattern of endorsement for themes from high and low integrators who indicated that integration of computer technologies fit with their instructional style generally reflected a similar pattern (see Figure 3). More responses were provided by high integrators than low integrators. There were some small differences in the overall pattern. For example, high integrators were more likely to indicate "comfort with computers" being 


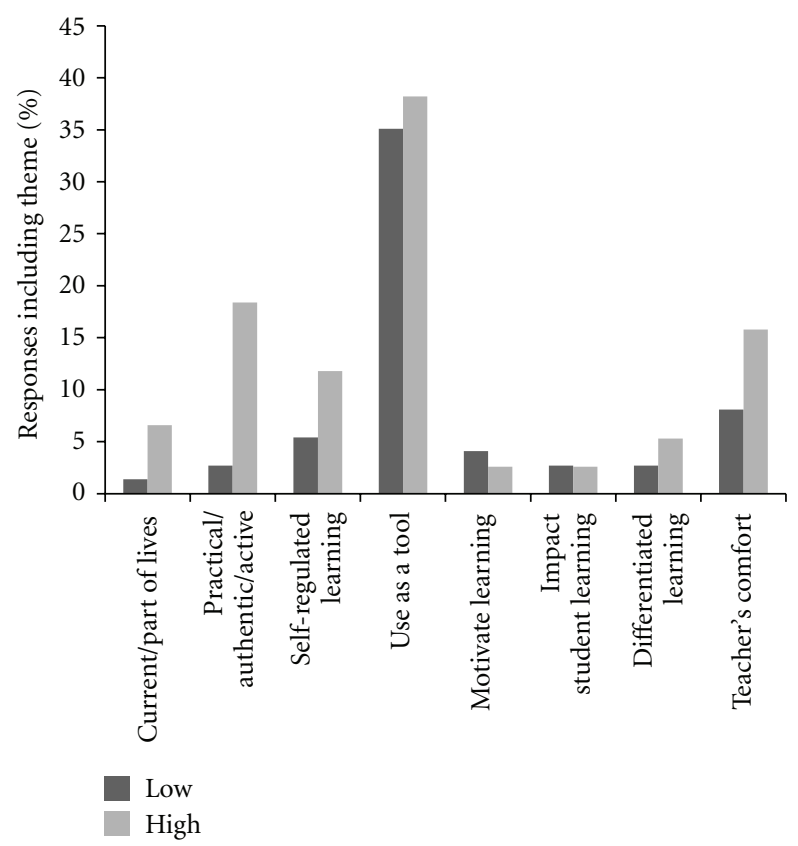

Figure 3: Patterns of themes by integration level to fit with instructional style.

a key reason that computers fit with their instructional style. The patterns of positive responses also differed in that high integrators saw the computer as a tool that provided authentic learning experiences and promoted self-regulation much more than did low integrators. Again, constructivist approaches where the learner is an active participant seem to be more consistent with computer integration.

With respect to respondents who did not believe integration of computer technologies matched their instructional style, the pattern of theme endorsements between high and low integrators was not similar for 3 of the 5 themes (see Figure 4). Low integrators expressed great concern about restrictions (most often in reference to time or resources). Low integrators also mentioned lack of comfort as an important concern. What is interesting in these two themes is that the "low integrators" were not making strong statements against integration of computer technology in terms of instructional style. Indeed, most indicated that they saw computer technologies as another instructional tool. Instead, these low integrators identified barriers that inhibit their ability to be able to use computers as part of their instructional repertoire. The theme of "other methods" was also unique to low integrators. Upon further examination as a function of school level, this theme was evident only among elementary school teachers who felt that other instructional formats (e.g., group activities, discussion, etc.) promoted greater learning gains and a learning environment that was more consistent with their instructional style.

Overall, fit with instructional style elicited a number of themes some of which were specific to constructivist models of teaching. Interestingly when high and low integrators were examined, it was not the pedagogical issues that surfaced as concerns for low integrators but, instead, barriers. Although

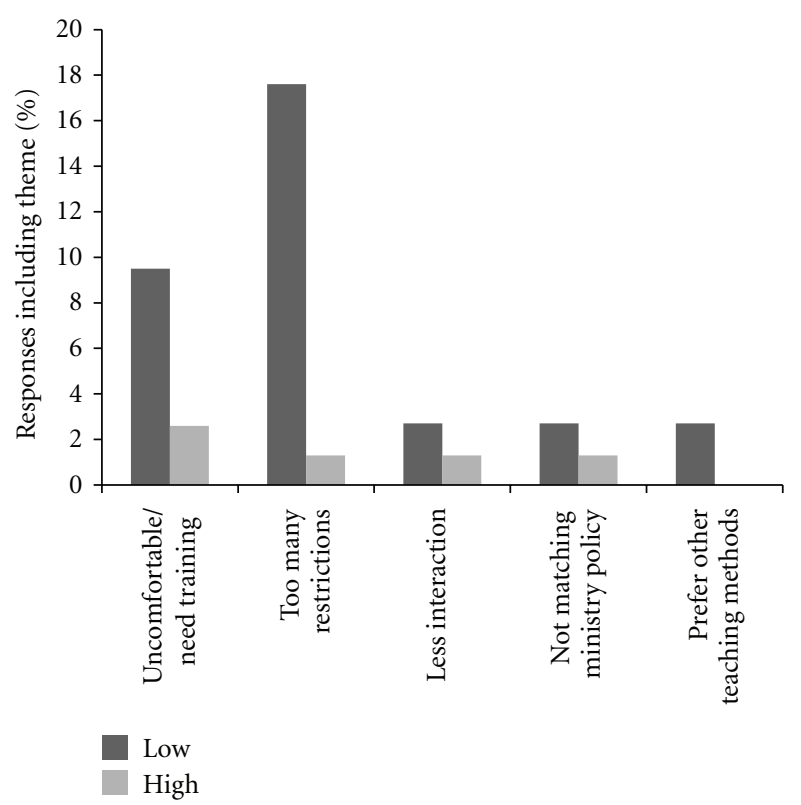

FIgURE 4: Patterns of themes integration level for integration of computer technology not fitting within personal instructional style.

the larger sample identified the potential of computer integration for providing differentiated, authentic, active learning opportunities, or promoting self-regulated learning, these were not the themes evident with low integrators supporting again the possibility that within our sample teachers may lack the resources and support to be able to overcome these barriers in order to see evidence of potential benefits from computer integration within their instruction.

3.5. Factors Influencing Planning with Computer Technology. Responses to the question regarding the factors that influence planning to use technology included six distinct categories. During the planning stage of computer integration, teachers are indicating that they consider what the computer technology will be used for in addition to factors related to teachers, students, resources, context/access, and external considerations.

A majority of responses included reference to the characteristics of the task to be completed or taught, including the goals and objectives of the task; amount of supervision required; time for project; research necessary; topics; and curriculum (e.g., "ease of use" or "how long it takes in comparison to a non computer based worksheet").

A second theme considered resources in terms of availability of suitable programs and computers; cost; time availablility; and consideration about whether computer technologies will work (e.g., "cheaper than photocopying" or "how many students versus number of computers, how much time we have"). An additional theme related to resources was the context or access to computers (e.g., "availability of computer lab" or "if the timing of the unit falls on computer day"). 


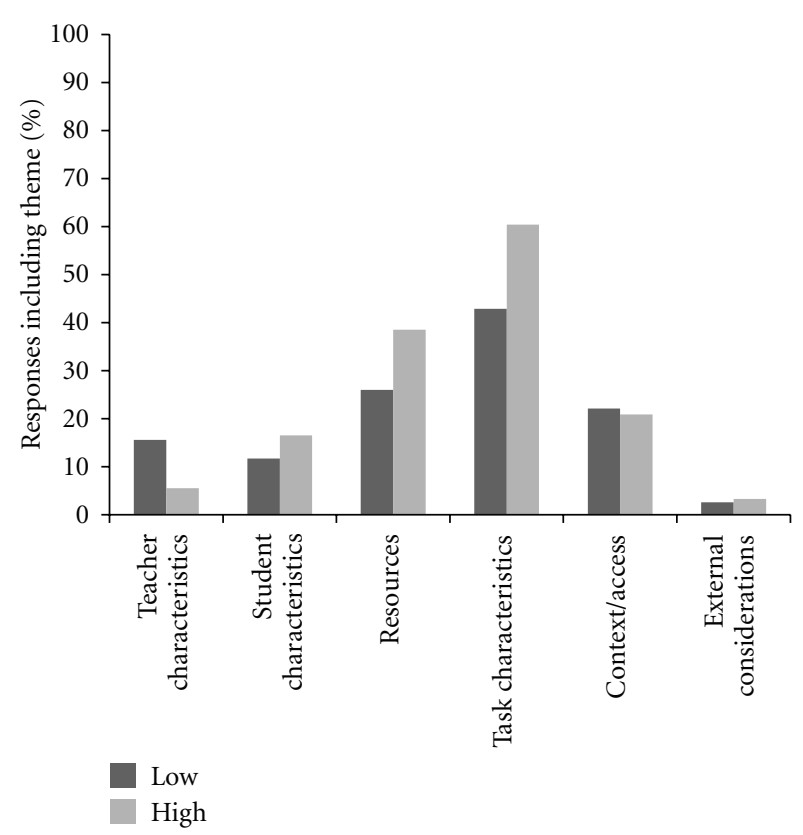

Figure 5: Patterns of themes by integration level for factors considered when planning to integrate computers in a lesson/unit.

The fourth and fifth themes considered characteristics of students and characteristics of teachers. Responses related to student characteristics included references to the characteristics and skill level of students; their ability to work independently; and the impact of technology on student learning (e.g., "age of students" or "previous knowledge of [both teacher] and student"). In considering teacher characteristics, participants talked and wrote about the teacher's own knowledge level and comfort with computer technology; teaching philosophy or theory of learning; and time to learn (e.g., "previous knowledge of both teacher and student" or "programs that I am familiar with").

A final theme extracted from factors influencing planning for technology integration included external considerations - influences outside teacher, student and task (e.g., "feel pressured to use technology" or "cultural awareness").

Overall, these themes reflect a wide array of individual characteristics and environmental variables that impact planning. Teachers are clearly balancing many concerns when they make decisions regarding use of computer technology in their curriculum. Computer integration is a thoughtful, complex issue and teachers are weighing the use of computer technology in terms of personal goals, student needs, the nature of the task, and environmental considerations that include issues such as resources and access.

3.6. Comparison of High and Low Integrators on Factors Influencing Planning by Level of Integration. Looking at the patterns of themes by level of integration (see Figure 5) -although there are differences in the numbers of teachers responding within each theme-the overall pattern of responses is similar for both groups. Both groups most often consider the characteristics of the task when planning to use technology. Low integrators had slightly greater endorsement of teacher characteristics again suggesting that teacher issues related to comfort, planning time, and so forth, which arose in themes for previous questions are pervasive across the questions being examined. The similar pattern of considerations yet different outcomes (i.e., high versus low integration) suggests that teachers might find different answers, for example, if a teacher is planning tasks that do not require the features of computer technology, they will be less likely to integrate it, while the teachers who are more fully integrating computers may be looking at tasks that are supported by computers and match a more self-regulated, independent task as suggested by the themes extracted from the question around fit with philosophy.

3.7. Characteristics of Excellent Teachers and Excellent Teachers Who Use Technology. Initially, these two questions were coded independently, but it became evident that the coding overlapped enormously suggesting that excellent teachers possessed particular attributes with the difference between general excellence and excellence including technology reflecting differences in the weighting of these attributes rather than the type of attribute. Overall, teachers were forthcoming with a variety of positive attributes for excellent teachers and they generally listed characteristics rather than providing a statement or explanation. Specific characteristics were grouped characteristics into more general, abstract categories resulting in six themes: knowledge (content/pedagogical and technological); relationships; teaching style; learning style; and other.

Responses categorized under content/pedagogical knowledge included characteristics that referred to a teacher's general or subject specific knowledge as well as their knowledge of current and appropriate pedagogical knowledge (e.g., "competence, knowledge of curriculum, knowledgeable in a number of areas, skilled and able to work with all abilities, up to date with curriculum").

Technological knowledge referred to a teacher's specific knowledge of technology and/or experience with computer technology (e.g., "computer brain, practical experience, teach technological studies, love of technology").

A third category mentioned in a large majority of responses included characteristics that described a teacher's relationships with others, how they treated students and colleagues (e.g., "ability to connect with kids, caring, compassionate, dedicated, empathetic, fair, understanding”).

Teachers also frequently made reference to teaching style, that is, how teachers presented information, how they actually taught (e.g., "clarity of thought, confident, enthusiastic, good class management skills, organized, willingness to release control").

In concert with teaching style, many participants also referred to a teacher's learning style in defining excellence. This category included characteristics describing how a teacher learned and kept current with teaching strategies and knowledge (e.g., "accepts feedback and uses it, adaptable, flexible, lifelong learners, passionate about their subject, risktakers, willing to experiment"). 
The remaining characteristics that were mentioned were captured by a theme labelled as "other" and included characteristics that did not fit in the above categories (e.g., "age, time, thick skinned").

Overall, the characteristic most commonly cited as important for excellent teachers in general was "relationships" with "learning style" and "teaching style" also being identified by a majority of teachers. It is noteworthy that there were a great number of personal characteristics recognized as critical for teaching excellence. The "knowledge" characteristics (content, pedagogical and technological knowledge) were less frequently cited as determinants of "excellent" teachers.

An important question for us was whether teachers who integrate technology were perceived as differing in characteristics from excellent teaching peers who did not integrate technology. A much smaller percentage of participants responded to the question about the difference between excellent teachers who used technology and those who did not suggesting that they did not see a difference. Anecdotally, there were some comments written in and directed to the researchers that the question suggested that teachers cannot be excellent without using technology and the participants did not agree with that statement so they chose not to respond to the question. The question was carefully written to avoid the suggestion that technologyusing teachers were better, but some participants apparently interpreted it to mean just that.

Although participants used the same characteristics to describe excellent teachers and excellent teachers who use technology, there were interesting differences in the prevalence of themes. Not surprisingly, "technological knowledge" was identified as a key characteristic that differentiates excellent teachers who use technology and those who do not. Of particular interest is that many responses to what makes excellent technology-using teachers different fit into the category identified as "other"-in this case other frequently referred to "having the time." Although "having time" is not necessarily a personal attribute, it does speak to the perceived demands that integrating technology imposes on teachers. In fact, time has been identified as both a barrier and support to computer integration [49] with more time being equated with greater integration. Although it is possible that the need for more time may be a consideration for all teachers proposing to integrate computers, it might also be important to consider teachers' perceptions about time needed to achieve this task. For example, experienced teachers who already have content and pedagogical expertise may have the "time" to consider integrating computer technology as an additional tool for instruction. Whereas, teachers who are not as experienced may not have the additional time required for integration of computer technology. This relationship between perceived time and experience is consistent with the characteristics attributed to excellent teachers. The "content/pedagogical knowledge" theme for this question yielded references to "being current and up to date" or "knowledgeable about content or pedagogy" in general.

Although relationships and teaching style were also present as themes, these themes did not occur as frequently

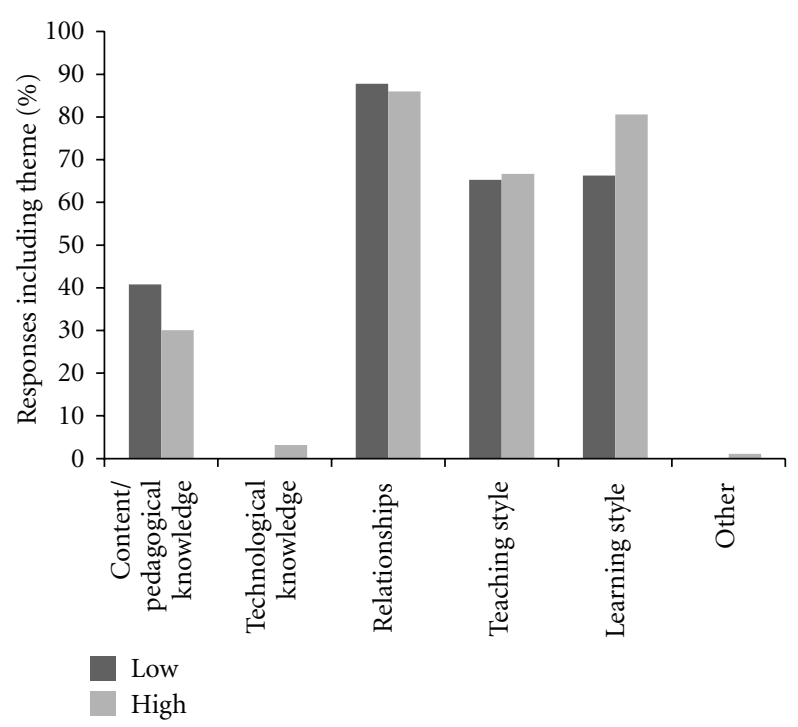

Figure 6: Patterns of themes by integration level for the personal characteristics of people who are excellent teachers.

when discussing excellence in integrating technology. Surprisingly, although the majority of teachers support computer technology as a cognitive tool, the defining characteristic of those who use technology was more frequently the learning style of the teacher rather than their instructional style. It may be that this philosophy is not seen as unique in supporting technology but that teachers who are successful in overcoming the barriers to its integration are flexible, adaptable, life-long learners, as described in the "learning style" theme.

\subsection{Comparison of High and Low Integrators on Charac-} teristics of Excellent Teachers. Figure 6 clearly demonstrates that high and low integrators have very similar views of the characteristics that make an excellent teacher, with a small difference associated with "learning style," with high integrators more frequently including this theme in their answers. Specifically, this difference suggests that teachers who were high integrators may see excellent teachers as different types of learners than did low integrators.

\subsection{Comparison of High and Low Integrators on Character-} istics of Excellent Teachers Who Use Technology. The limited number of responses to this question suggests that the majority of teachers did not perceive excellent teachers to be different from excellent teachers who integrate technology (see Figure 7). However, both high and low integrators responded to the question suggesting that both teachers who integrate technology may see themselves as different from their colleagues, as well as those who do not integrate computer technology, perhaps because they do not see themselves as having the characteristics that they listed. Interestingly, similar to the description of excellent teachers, the learning style theme along with technological knowledge emerged as an important and more pronounced characteristic for excellent teachers who integrate technology. Excellent 


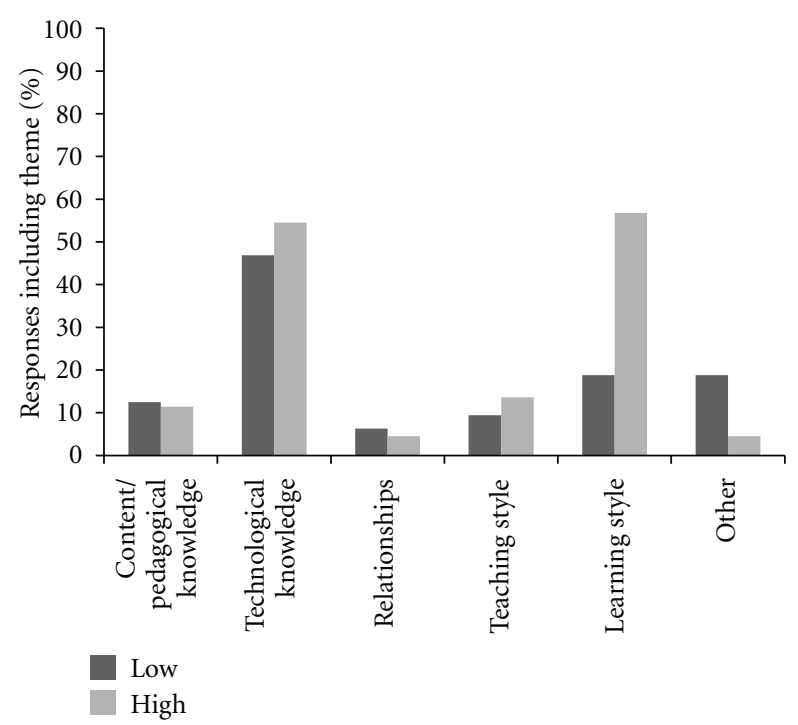

Figure 7: Patterns of themes by integration level for the characteristics that make excellent teachers who happen to integrate technology effectively, different from teachers who do not.

technology-using teachers were described as risk-taking, open-minded, flexible, and adaptive suggesting that high integrators endorse the importance of this type of learning style as a more critical feature for identifying teachers likely to demonstrate excellence when integrating technology.

\section{Conclusions}

The complexity of teacher change and school reform coupled with the rapid change of technological innovations has made it difficult to identify and integrate the individual and environmental factors that impact computer integration. Computer technology, by its nature, is complex and difficult to implement. Koehler and Mishra [50] suggest that technology is not "transparent" to the user. That is, digital technologies, such as computers, are "protean" (have multiple uses); "unstable" (rapidly changing); and "opaque" (how they actually work is hidden from the user). This lack of transparency can create the perception that computer technologies are difficult to implement and removed from the current practice of many teachers, making it less likely that a teacher will adopt technology [12]. However, the vast majority of participants in this study supported the integration of computer technology.

Results of the current study support the hypothesis emerging from recent work identifying the teacher as the key to successful integration of technology (e.g., $[2,51]$ ). Trying to understand why teachers did or did not support integration was facilitated by providing teachers with an opportunity to explain their attitudes and beliefs, and, hence, a richer understanding was achieved. For example, rather than simply asking whether, or how much, technology fits, or does not fit, with their instructional style, we were able to extract the specific features of computer technology that may not support their teaching philosophy by providing a forum where teachers could explain their responses. Although teachers did not always directly state their "instructional style," they described the potential of computer technology using language related to constructivist, individualized instruction, such as "authentic tasks," "self-regulated learning," "current part of students' lives." Generally, responses were positive in terms of technology fitting with instructional style, such as "I use computers to demonstrate concepts and show new ways of doing things;" "as a computer science teacher, I use a different style. I'm mainly a resource. I feel comfortable with this. However, I understand how traditional classroom teachers have problems adjusting to a lab given the way I change my style in a non-computer math classroom;" and "I like how computers engage my students and motivate them. I like how they allow students to be selfdirected."

Those teachers that did not see a fit were citing restrictions due to time and resources as reasons, rather than philosophical disagreements. For example, "Due to personal obligations at home, I truly do not always have time to plan for use of computes properly;" "I'd love to use it more but there are many restrictions such as not having enough computers to teach a class;" and "I do not think about using computers except for student research because it is such a hassle getting computer access. And they are slow. Waste too much time if they break down." These issues related to time were pervasive and reappeared when teachers identified time as a characteristic of excellent computer using teachers. Clearly, time and resources continue to be ongoing barriers to successful integration $[2,24]$. Excellent technology-using teachers were also described as having a different learning style-being risk-takers, flexible, and continuous learners. This suggests that those teachers may have the personality as well as the time to overcome any barriers to integration that might stand in the way of their positive beliefs about computer integration while other teachers may not have the characteristics or time to address computer integration.

Those teachers who are integrating technology as a valuable cognitive tool may have reached a level of understanding of the technological pedagogical content knowledge that Mishra and Koehler [25] suggest is necessary for successful integration of technology. Emphasis is on task characteristics and student learning and how they can be supported with computer technology rather than on the technology itself. Teachers who are still reporting barriers to computer integration may need to expand their understanding of how the content, pedagogy, and technology interact [25], as the teacher who said "as a newer teacher, it is sometimes hard to integrate subjects, let alone computers." Teachers may need to have an integrated understanding and confidence in all aspects of teaching to successfully integrate technology into their teaching.

Issues regarding comfort with technology suggest that some teachers may still require more training and support. It may be that those teachers need access to training that is "just-in-time" and addresses their current teaching methods rather than learning to integrate technology through a more independent, risk-taking approach that high integrator might use. Individualized support and training that is 
directed at tasks that match the capabilities of the technology may be necessary for teachers who do not integrate on their own.

A salient issue identified in the present research concerns teachers' responses to what makes an excellent teacher and how excellent technology-using teachers may or may not be different. Specifically, although teachers see characteristics that support relationships (caring, compassionate, dedicated, empathetic, sense of humor) to be most important in excellent teachers, it was mentioned less in describing technology using teachers, suggesting that that is not a difference but a foundation for excellent teachers. However, the learning style of the technology-using teachers along with their technological knowledge was key distinguishing characteristics and this distinction was particularly salient for high integrators. Teachers who integrate were considered "life-long learners" and "problem-solvers" who are "flexible." These depiction of excellent teachers who use technology is consistent with extant models such as Koehler and Mishra [50] who suggest that "TPK [technological pedagogical knowledge] requires forward-looking, creative and openminded seeking of technology, not for its own sake, but for the sake of advancing student learning and understanding" (page 17). Overall, these traits suggest that technologyusing teachers need some level of technological expertise or knowledge but also need to be life-long learners who are willing to experiment and take risks.

Although teachers did not directly identify their teaching philosophy, they used internal representations of their "instructional style" in deciding if technology fit with that style and whether or not they supported computer integration for their students. Teachers who saw technology fitting with their instructional style gave responses that described the potential of computer technology as a cognitive tool, for example, valuable resource, self-regulated learning, current tool, and so forth. Those who did not see a philosophical fit were fewer in number and their responses fit in themes that were related to computer comfort, resources, curriculum, and pedagogy that did not match their preferences. Once again, some teachers, who see a fit between their teaching and computer technology, are not only considering their technological knowledge and comfort but also looking at technology in the context of teaching and learning. Our findings suggest that learning about technology, then, needs to be directly connected to tasks, content, and the appropriate pedagogy.

\section{Implications}

The implications of these results support the idea that teacher characteristics, beyond knowledge (TPACK) [25], are indeed an important, perhaps crucial, factor in successful integration of computer technologies. Successful models of computer integration should include what prior research suggests, that is, knowledge, experience, and support (e.g., $[2,25,26,50])$ as well as individual teacher characteristics. Professional development or training should appeal to the individual learning styles and experiences of the teachers involved and must be directed at their specific personal characteristics and goals as well as presenting concrete examples of using technology as a cognitive tool in order to promote computer integration in this digital age.

Those teachers who are already integrating computer technology support a constructivist, self-regulated, independent approach to learning and instruction and see lifelong learning as a necessary part of computer technology integration. Professional development for teachers who do not share the same characteristics may require a completely different approach, directed at removal of barriers such as resources and knowledge, and direct matching of tasks to technology. Teachers who are not risk takers will need to see the integration of computer technology as "less risky" before it is fully integrated.

\section{Acknowledgments}

The authors would like to acknowledge the assistance and participation of the Waterloo Region District School Board Computers Across the Curriculum Committee, as well as the educators involved in this study. This project was partially funded by the generous support of the Social Sciences and Humanities Research Council of Canada.

\section{References}

[1] P. C. Abrami, "Understanding and promoting complex learning using technology," Educational Research and Evaluation, vol. 7, no. 2-3, pp. 113-136, 2001.

[2] J. Mueller, E. Wood, and T. Willoughby, "The integration of computer technology in the classroom," in Children's Learning in a Digital World, T. Willoughby and E. Wood, Eds., pp. 271298, 2008.

[3] R. G. Muir-Herzig, "Technology and its impact in the classroom," Computers \& Education, vol. 42, no. 2, pp. 111-131, 2004.

[4] S. Aduwa-Ogiegbaen, "Nigerian inservice teachers' selfassessment in core technology competences and their professional development needs in ICT," Journal of Computing in Teacher Education, vol. 26, no. 1, pp. 17-28, 2009.

[5] L. Cuban, H. Kirkpatrick, and C. Peck, "High access and low use of technologies in high school classrooms: explaining an apparent paradox," American Educational Research Journal, vol. 38, no. 4, pp. 813-834, 2001.

[6] M. Drent and M. Meelissen, "Which factors obstruct or stimulate teacher educators to use ICT innovatively?" Computers \& Education, vol. 51, no. 1, pp. 187-199, 2008.

[7] H. Ertl and J. Plante, Connectivity and Learning in Canada's Schools, No. 56F0004MIE-No. 011, Science, Innovation and Electronic Information Division, Statistics Canada, Ottawa, Canada, 2004.

[8] C. P. Lim and M. S. Khine, "Managing teachers' barriers to ICT integration in Singapore schools," Journal of Technology and Teacher Education, vol. 14, no. 1, pp. 97-125, 2006.

[9] L. D. Rosen and M. M. Weil, "Computer availability, computer experience and technophobia among public school teachers," Computers in Human Behavior, vol. 11, no. 1, pp. 9-31, 1995.

[10] S. C. Yang and Y. F. Huang, "A study of high school English teachers' behavior, concerns and beliefs in integrating information technology into English instruction," Computers in Human Behavior, vol. 24, no. 3, pp. 1085-1103, 2008. 
[11] L. Johnson, R. Smith, H. Willis, A. Levine, and K. Haywood, The 2011 Horizon Report, The New Media Consortium, Austin, Tex, USA, 2011.

[12] Y. Zhao, K. Pugh, S. Sheldon, and J. L. Byers, "Conditions for classroom technology innovations," Teachers College Record, vol. 104, no. 3, pp. 482-515, 2002.

[13] J. H. Sandholtz, C. Ringstaff, and D. C. Dwyer, Teaching with Technology. Creating Student-Centred Classrooms, Teachers College Press, New York, NY, USA, 1997.

[14] M. Huberman, "Linking the practitioner and researcher communities forschool improvement," Keynote Address at the International Congress for School Effectiveness and Improvement, Victoria, BC., Canada, 1992.

[15] R. Anderson and A. Ronnkvist, "The presence of computers in American schools," Teaching, Learning and Computing: A research project of the Center for Research on Information Technology and Organizations, 1999, http://www.crito.uci.edu/tlc/ findings/computers_in_american_schools/.

[16] M. Castro and L. Alves, "The implementation and use of computers in education in Brazil: Niterói city/Rio de Janeiro," Computers \& Education, vol. 49, no. 4, pp. 1378-1386, 2007.

[17] Statistics Canada, "Learning-computers access in schools," Indicators of Well-being in Canada, 2009, http://www4.hrsdc .gc.ca/.3ndic.1t.4r@-eng.jsp?iid=28.

[18] T. Conlon and M. Simpson, "Silicon Valley versus Silicon Glen: the impact of computers upon teaching and learning: a comparative study," British Journal of Educational Technology, vol. 34, no. 2, pp. 137-150, 2003.

[19] M. Ciftci and S. Kurt, "Barriers to teachers' use of technology," International Journal of Instructional Media, vol. 39, no. 3, pp. 225-238, 2012.

[20] E. Judson, "How teachers integrate technology and their beliefs about learning: is there a connection?" Journal of Technology and Teacher Education, vol. 14, no. 3, pp. 581-597, 2006.

[21] R. Hermans, J. Tondeur, J. van Braak, and M. Valcke, "The impact of primary school teachers' educational beliefs on the classroom use of computers," Computers \& Education, vol. 51, no. 4, pp. 1499-1509, 2008.

[22] R. Kadel, "How teacher attitudes affect technology integration," Learning \& Leading with Technology, vol. 32, no. 5, pp. 34-35, 47, 2005.

[23] R. A. Vannatta and N. Fordham, "Teacher dispositions as predictors of classroom technology use," Journal of Research on Technology in Education, vol. 36, no. 3, pp. 253-271, 2004.

[24] L. Wozney, V. Venkatesh, and P. Abrami, "Implementing computer technologies: teachers' perceptions and practices," Journal of Technology and Teacher Education, vol. 14, no. 1, pp. 173-207, 2006.

[25] P. Mishra and M. J. Koehler, "Technological pedagogical content knowledge: a framework for teacher knowledge," Teachers College Record, vol. 108, no. 6, pp. 1017-1054, 2006.

[26] J. Mueller, "Observational measures of technological, pedagogical, content knowledge (TPACK) in the integration of laptop computers in elementary writing instruction," in Proceedings of the 21st Society for Information Technology \& Teacher Education International Conference, San Diego, Calif, USA, March 2010.

[27] M. J. Koehler and P. Mishra, "What is technological pedagogical content knowledge?" Contemporary Issues in Technology in Teacher Education, vol. 9, no. 1, pp. 60-70, 2009.

[28] J. E. Brophy and T. L. Good, "Teacher behavior and student achievement," in Handbook of Research on Teaching, M. C.
Wittrock, Ed., pp. 328-375, Macmillan, New York, NY, USA, 3rd edition, 1986.

[29] M. Buchmann, "Teaching knowledge: the lights that teachers live by," Oxford Review of Education, vol. 13, no. 2, pp. 151164, 1987.

[30] A. T. Lumpe, J. J. Haney, and C. M. Czerniak, "Assessing teachers' beliefs about their science teaching context," Journal of Research in Science Teaching, vol. 37, no. 3, pp. 275-292, 2000.

[31] J. Nespor, "The role of beliefs in the practice of teaching," Journal of Curriculum Studies, vol. 19, no. 4, pp. 317-328, 1987.

[32] J. H. van Driel, D. Beijaard, and N. Verloop, "Professional development and reform in science education: the role of teachers' practical knowledge," Journal of Research in Science Teaching, vol. 38, no. 2, pp. 137-158, 2001.

[33] P. A. Ertmer, "Teacher pedagogical beliefs: the final frontier in our quest for technology integration?” Educational Technology Research and Development, vol. 53, no. 4, pp. 25-39, 2005.

[34] P. A. Ertmer, A. T. Ottenbreit-Leftwich, O. Sadik, E. Sendurur, and P. Sendurur, "Teacher beliefs and technology integration practices: a critical relationship," Computers \& Education, vol. 59, no. 2, pp. 424-435, 2012.

[35] E. McGrail, "Teachers, technology, and change: English teachers' perspectives," Journal of Technology and Teacher Education, vol. 13, no. 1, pp. 5-24, 2005.

[36] D. S. Niederhauser and T. Stoddart, “Teachers' instructional perspectives and use of educational software," Teaching and Teacher Education, vol. 17, no. 1, pp. 15-31, 2001.

[37] M. Windschitl and K. Sahl, "Tracing teachers' use of technology in a laptop computer school: the interplay of teacher beliefs, social dynamics, and institutional culture," American Educational Research Journal, vol. 39, no. 1, pp. 165-205, 2002.

[38] J. Lei, "Digital natives as preservice teachers: what technology preparation is needed?" Journal of Computing in Teacher Education, vol. 25, no. 3, pp. 87-97, 2009.

[39] D. Marks, "Literacy, instruction, and technology: meeting millennials on their own turf," AACE Journal, vol. 17, no. 4, pp. 363-377, 2009.

[40] G. Sang, M. Valcke, J. van Braak, and J. Tondeur, "Student teachers' thinking processes and ICT integration: predictors of prospective teaching behaviors with educational technology," Computers \& Education, vol. 54, no. 1, pp. 103-112, 2010.

[41] N. Mercer and E. Fisher, "How do teachers help children to learn? An analysis of teachers' interventions in computerbased activities," Learning and Instruction, vol. 2, no. 4, pp. 339-355, 1992.

[42] W. L. Sanders and S. P. Horn, "The tennessee value-added assessment system (TVAAS): mixed-model methodology in educational assessment," Journal of Personnel Evaluation in Education, vol. 8, no. 3, pp. 299-311, 1994.

[43] K. S. Shapley, D. Sheehan, C. Maloney, and F. CaranikasWalker, "Evaluating the implementation fidelity of technology immersion and its relationship with student achievement," The Journal of Technology, Learning, and Assessment, vol. 9, no. 4, pp. 1-69, 2010.

[44] N. Valanides and C. Angeli, "Professional development for computer-enhanced learning: a case study with science teachers," Research in Science \& Technological Education, vol. 26, no. 1, pp. 3-12, 2008.

[45] A. Strauss and J. Corbin, Basics of Qualitative Research: Grounded Theory Procedures and Techniques, Sage, Newbury Park, Calif, USA, 1990.

[46] E. G. Guba and Y. S. Lincoln, Fourth Generation Evaluation, Sage, Newbury Park, Calif, USA, 1989. 
[47] T. Y. Şahin, “Students teacher's perceptions of instructional technology: developing materials based on a constructivist approach," British Journal of Educational Technology, vol. 34, no. 1, pp. 67-74, 2003.

[48] R. E. Boyatzis, Transforming Qualitative Information: Thematic Analysis and Code Development, Sage, Thousand Oaks, Calif, USA, 1998.

[49] J. Mueller, E. Wood, T. Willoughby, C. Ross, and J. Specht, "Identifying discriminating variables between teachers who fully integrate computers and teachers with limited integration," Computers \& Education, vol. 51, no. 4, pp. 1523-1537, 2008.

[50] M. J. Koehler and P. Mishra, "Introducing TPCK," in Handbook of Technological Pedagogical Content Knowledge (TPCK) for Educators, AACTE Committee on Innovation and Technology, Ed., pp. 3-29, Routledge and the Taylor \& Francis, New York, NY, USA, 2008.

[51] J. L. Fisler and W. A. Firestone, "Teacher learning in a schooluniversity partnership: exploring the role of social trust and teaching efficacy beliefs," Teachers College Record, vol. 108, no. 6, pp. 1155-1185, 2006. 


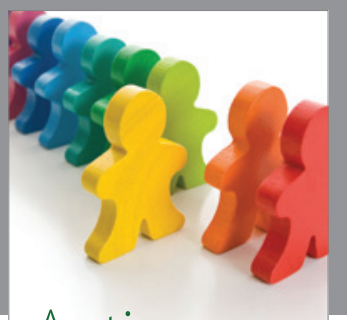

Autism

Research and Treatment
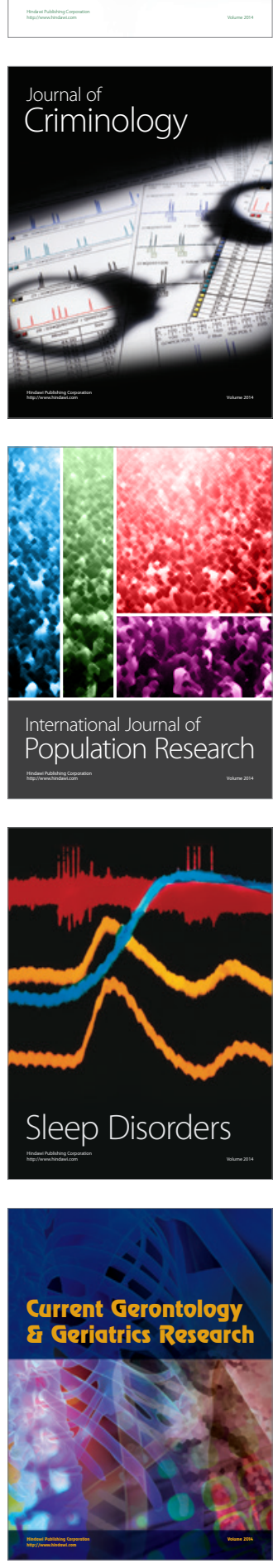
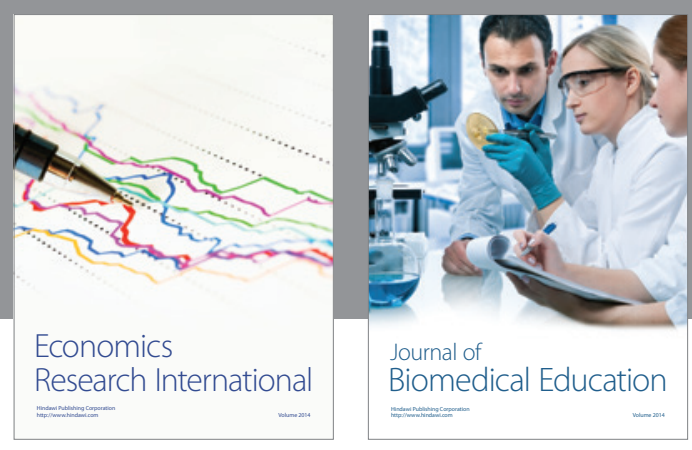

Journal of

Biomedical Education

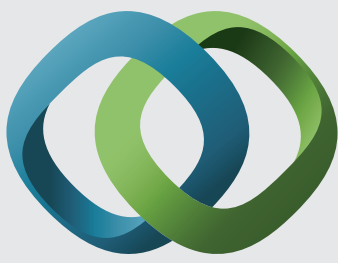

\section{Hindawi}

Submit your manuscripts at

http://www.hindawi.com
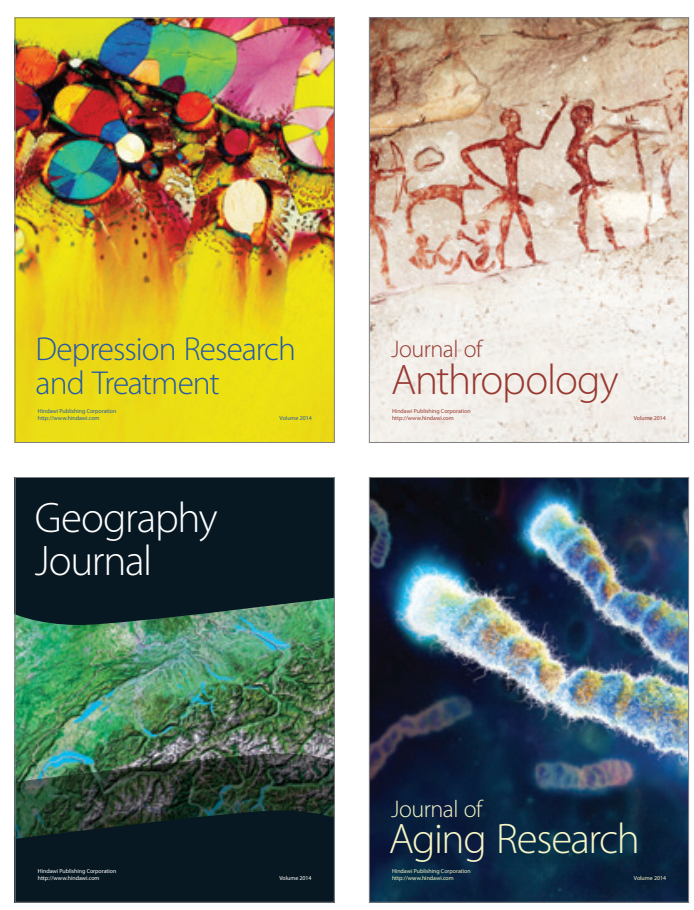

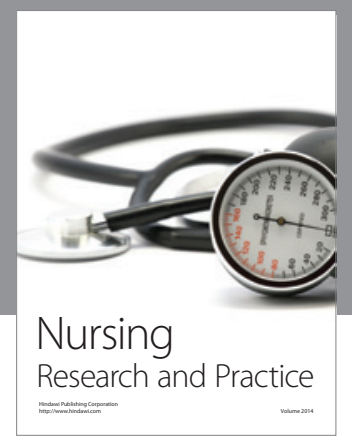

Nursing

Research and Practice

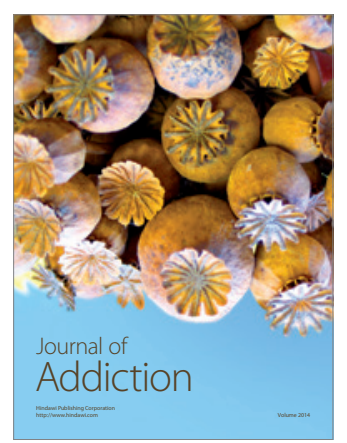

Child Development

Research

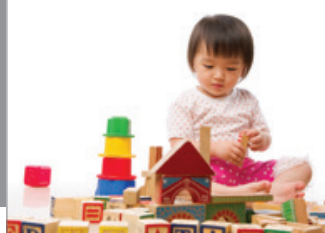

迥
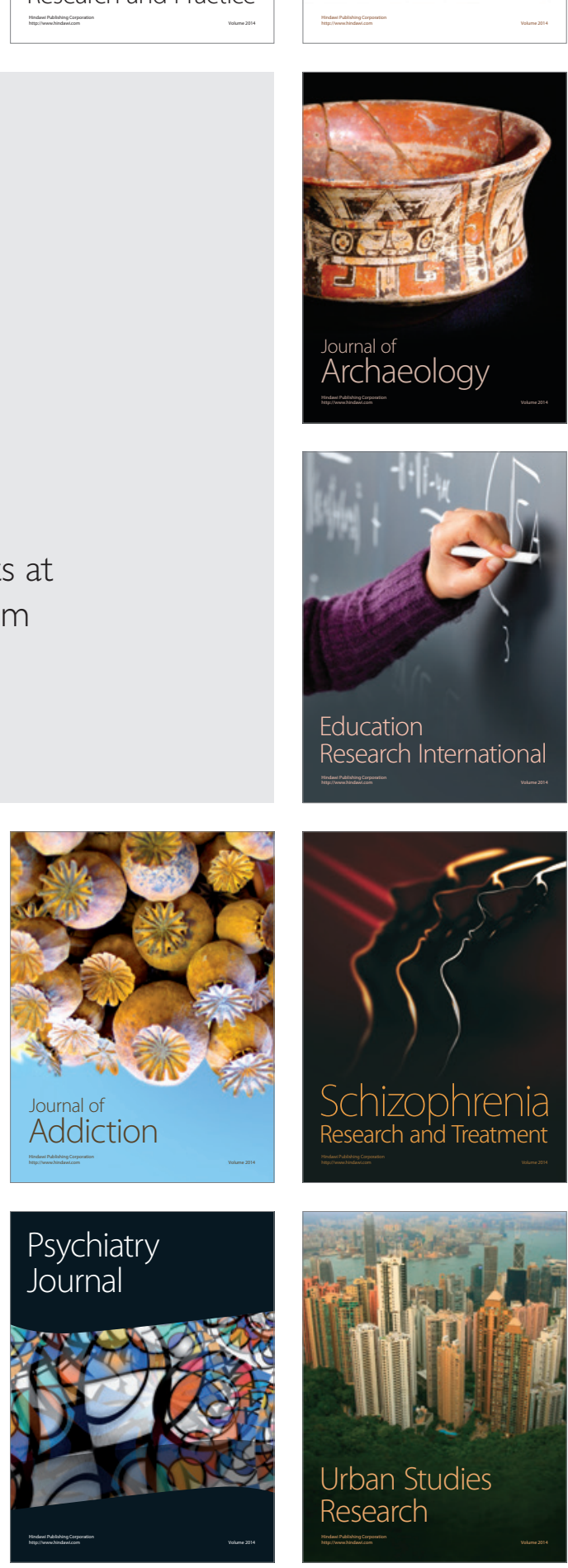